\title{
ÉTICA DE LA COMUNICACIÓN
}

Javier Sádaba

Universidad Autónoma de Madrid

1. La comunicación es un concepto muy amplio por lo que se puede hablar de ella desde distintos ángulos. En el terreno filosófico, por ejemplo y en los últimos años, algunos autores han intentado construir, al menos idealmente, una sociedad en la que la comunicación resplandeciera de tal manera que todos los individuos pudiéramos razonar y elegir con una transparencia casi celestial (me refiero, para aquellos que estén interesados en el tema, a filósofos como los muy citados Habermas o Apel). Pero el tema importa también a la psicología, a la antropología y a otros campos más. Piénsese, y es un ejemplo entre mil, en las técnicas de comunicación de masas. En algunos países, en EEUU en concreto, están teniendo un éxito (contemplado tal éxito desde el punto de vista externo) extraordinario. Tanto es así que charlatanes que no llegarían, en circunstancias normales, a reunir a una comunidad de vecinos, logran que les escuchen y sigan millones de personas. Por otro lado, la comunicación ha estado ligada, y es normal, a la información. Y la información se ha tecnificado de manera espectacular en las recientes décadas. Se habla de información genética (de bioinformática, por ejemplo), de psicología cognitiva (en donde se estudian los mecanismos según los cuales procesamos la información -con el cerebro siempre, naturalmente) y, sobre todo, de la teoría de la información en cuanto tal. Hoy se habla de TIC, de CMSI, de ITU y de una larga fila de siglas que expresan cómo nos estamos moviendo, al igual que en los mensajes por medio de móviles, en una sopa de letras (el viejo Marcuse ya predijo en uno de sus libros que, al final, la información iba a estar tan codificada que desapareceríamos los mensajeros, siendo suplidos por el puro mensaje).

Pero detrás de todo ello, insisto, hay una muy desarrollada teoría de la información. Tal teoría, y en sus aspectos más elementales, distingue entre la fuente o emisión de la información (los bits, que con el átomo y el gen son los tres grandes descubrimientos del siglo que acabamos de dejar), el medio o canal, y el receptor. En un paso más se necesita saber de matemáticas para introdu- 
cirse en el laberinto informático. El caso típico es el alfabeto en donde con pocas letras enviamos y recibimos una cantidad casi infinita de información. Con $n$ símbolos, por ejemplo, los mensajes de longitud $m$ son $n^{m}$. Y desde ahí las fórmulas se complican aún más. Como no quiero meterme en laberinto alguno y sí referirme, de la manera más clara posible, a lo que creo que debería entenderse hoy por «ética de la comunicación», voy a dejar lo expuesto en pura indicación. Una indicación que considero, sin embargo, necesaria si queremos conocer cuál es el contexto en el que se desenvuelve nuestra vida. Valga lo visto hasta el momento, por tanto, como introducción o puesta en escena de lo que sigue.

2. Me referiré a la comunicación en su sentido más cotidiano. Y eso nos obliga a recordar que los humanos somos animales con lenguaje y que interactuamos en un sinfín de modalidades. Como ha solido afirmarse, podemos ser Quijotes pero difícilmente podemos ser Robinsones. El paso de los primates a los humanos se manifiesta, precisamente, en la característica citada; es decir, en la aparición del lenguaje articulado y predicativo. Contra ciertos sociobiólogos que nos asimilan a los insectos sociales o contra aquellos que sólo ven una leve diferencia entre los simios y el Homo Sapiens debemos oponer un hecho innegable: realizamos libremente una serie de funciones y tales funciones consisten en intercambiar conocimientos y afectos. $Y$ lo hacemos de una manera especial. Por ejemplo, hablando de lo que existe y de lo que no existe. O con un altruismo (cuando se da) que va más allá del [nivel] biológico; en otros términos, somos capaces de ponernos en la piel del otro, de reconocernos en los demás, de crear, en suma, una sociedad en la que cada uno cuenta, al menos teóricamente, como el resto y en donde todos necesitamos de todos. Tal intercambio, en el que son necesarios símbolos, se desenvuelve en el reino de la cultura. Y aunque cultura, entendida ésta como transmisión social de habilidades y conocimientos, también se da en grado rudimentario en los chimpancés, sólo nosotros creamos ciencia, arte o, cosa para mí más decisiva, ética o moral (que como sinónimos los tomaré, a no ser que necesite hacer alguna distinción pertinente).

Efectivamente, la moral quizás sea la construcción más grandiosa que hemos creado los seres humanos. Aristóteles escribía que con la ética nos cuasidivinizamos. Y es que, siendo morales, nos convertimos en artistas de nosotros mismos. No se trata, sin más, de una metáfora. Controlar la propia libertad, intentar acomodarla a la de los demás y edificar un conjunto de relaciones en las que vayamos creciendo en humanidad es más admirable que cualquier descubrimiento científico que le robemos a la naturaleza o que cualquier obra de arte ante la que nos quedemos extasiados. En este punto la ética y la comunicación se nos revelan, si no como dos gemelos, sí como dos procesos que van íntimamente unidos. Somos morales fundamentalmente respecto a los demás. La justicia, por ejemplo, se consigue, cuando se consigue, equilibrando los bienes y las cargas comunes. Y la eliminación de la miseria que, además de otro ejemplo, es una asignatura pendiente que debería avergonzarnos sólo pensar 
en ella, se obtendría únicamente si somos capaces de comunicarnos en igualdad de derechos con los que no logran siquiera sobrevivir. Todo ello requiere que pongamos en pie normas, consejos, acciones y movimientos que suponen, obviamente, distintos tipos de comunicación. No se es moral si uno no se comunica bien con los demás. Y si uno se comunica bien con los demás, está siendo, sin duda, moral.

Dentro de la coimplicación entre ética y comunicación me gustaría fijarme en este texto, de manera especial, en dos tipos de comportamiento. El primero podríamos Ilamarlo más pedagógico o individual. El segundo, y en el que me detendré más, sociopolítico. En los dos se hará patente hasta dónde alcanza la ética en nuestra forma de comunicarnos. Comencemos por el primero.

3. Hablar bien («como un abogado», que decían nuestras abuelas cuando querían poner como ejemplo de lo que llamaban «pico de oro» y que, por lo general, solía ser o un pedante o alguien, según los cínicos, con parrexia; esto es, de los que hablan y hablan sin parar, sin detenerse en si dicen algo o son pura vaciedad) no es, por sí mismo, un acto moral. Ahora bien, el uso del lenguaje no es neutro. Y el mimo por el lenguaje es esencial. Para filósofos como W. Benjamin y para toda una generación que fue como el canto del cisne de la cultura europea y que tuvo su sede en Viena a finales del siglo XIX y comienzos del $X X$, el lenguaje reflejaba a la perfección el tipo de persona que se era. $Y$ eso, sin caer en exageraciones absurdas, sigue siendo verdad. Un lenguaje tosco (que no austero), un lenguaje maleducado o un lenguaje pobre por inculto son parientes de la carencia de ética. Es conocida la frase que se atribuye a O. Wilde según la cual manners before morals. La frase tiene su punto de razón. Y lo tiene tanto en su sentido negativo como en el positivo. Dicho de otra manera, la tiene en su sentido negativo si con ello se quiere dar a entender que se es incapaz de comunicarse con los demás, que se es como una bola de billar y que se establecen relaciones con los otros como si éstos fueran simples objetos y no unos sujetos con los que nos relacionamos internamente (o, lo que es lo mismo, no mercantilizamos la relación con el resto de los individuos). Pero la tiene aún más en su sentido positivo. Como tal sentido positivo requiere una exposición adecuada, me detendré en ello con cierto detalle.

Me referí antes a la importancia del lenguaje como característica típicamente humana; no un lenguaje cualquiera, puesto que si por lenguaje se entiende dar a entender algo, también lo hacen los animales. Nuestro lenguaje es capaz de otra serie de funciones que trascienden lo que es la inmediatez y el estar limitados a un momento puntual y a un espacio puntual. $Y$ nuestro lenguaje se refiere, como sabemos y acabamos de ver, a bienes y males, y trata de dar razones de por qué algo es bueno y debe hacerse, o por qué algo no es bueno y, en consecuencia, no debe hacerse. El lenguaje de los humanos informa ( «ahora son las ocho y cuarto de la tarde»), manda («no se debe matar») y expresa ( «iqué bella es la melodía de Mozart o de Joaquín Rodrigo que estoy oyendo!»). 
Precisamente en la relación armónica de estas tres funciones consiste una también armónica actitud moral en la que se informa, se imponen deberes y se expresan sentimientos morales (de indignación, por ejemplo, ante un asesinato o de vergüenza propia, por ejemplo, por no ayudar cuando lo requiere y está en nuestro poder realizarlo). Ahora bien, a mí y en relación a nuestro tema ${ }^{1}$, me importaría señalar estas otras tres funciones del lenguaje que nos posibilitan, de modo positivo, ser realmente morales. Esas tres funciones son las siguientes: la lógica, la retórica y la dialéctica. Si se carece de ellas, la vida moral no se desarrolla. Cuando nos quejamos, y nos quejamos muchas veces con razón, de que los jóvenes (sin entrar ahora en si son mejores o peores que antes o en cuanto ha cambiado lo que entendemos por juventud) se muestran infantilizados o indiferentes ante los diversos valores a realizar, estamos, en el fondo, pidiendo una pedagogía de lo que son esas tres funciones mentadas y que en modo alguno exigen una formación académica especial para comprenderlas y, sobre todo, para llevarlas a la práctica. Son componentes esenciales de la comunicación. Y en cuanto tal, son componentes esenciales también de una vida moral real.

¿Qué es lo que quiero decir con la función lógica? La respuesta inmediata es ésta: hay que saber informar y esto implica que hay que decir lo que sucede. Decir qué es lo que está sucediendo es tanto como decir la verdad. No voy a hacer ahora una defensa cerrada de la verdad. En absoluto. La verdad no es un concepto cerrado, acepta e, incluso, exige excepciones y tiene sus grados. En caso contrario acabaríamos sosteniendo la macabra concepción defendida por Kant y según la cual habría que informar a dos malhechores que persiguen a un niño inocente si sabemos dónde se esconde para así no mentir. Pero la mentira o la ocultación son parásitas de la verdad; en otros términos, primero aprendemos a llamar a las cosas por su nombre y sólo más tarde aprendemos el juego de la mentira. La comunicación se vendría abajo si, por principio, no fuéramos veraces. Veraz es aquel que está dispuesto a decir lo que ocurre; o sea, la verdad. Una extraña secta persa (y según ciertas crónicas) estima tanto la verdad como la mentira. Los que les conocen cuentan que son un verdadero caos porque ni siquiera te dan la hora con aproximación. Yo no creo que nosotros vivamos en un mundo regido por la verdad. Como más adelante diré, pienso todo lo contrario. En lo elemental, sin embargo, utilizamos los signos que refieren a las cosas. $Y$ es que se trata de una labor esencial del lenguaje y sin la cual pereceríamos. La consecuencia inmediata que deseo sacar de esta función lógica (en un sentido del término «lógica» heredado de los griegos) es que si queremos comunicarnos mutuamente hay que ofrecer algún contenido; sin limitarse a abrir la boca o mantenerse en la más zafia vaciedad.

Es una lástima que no se eduque a utilizar bien y en orden las palabras. Y es una desgracia que nos estemos deslizando por el uso de palabras comodín que valen para todo, o en el lenguaje de la propaganda, la publicidad, el sensacionalismo, la seducción o tantos modos más de utilizar el lenguaje para no decir

\footnotetext{
${ }^{1} Y$ que es el de la comunicación.
} 
nada. En este caso ni siquiera se cae en el vicio de no ser veraces. Se es, sencillamente, frívolo. En suma, la función lógica del lenguaje es esencial para que nos comuniquemos y cuando una sociedad no muestra interés para que la verdad y la veracidad (lo objetivo y lo subjetivo) tengan la primacía que les corresponde o está enferma o es cada vez más sectaria o no se ha enterado de lo que el antes citado Benjamin llamaba «el puro nombrar» o dar su ser, por medio de la palabra, a las cosas.

Pasemos a la segunda función, a la retórica. Existe, y esto está en conexión con lo que acabo de exponer, una mala y una buena retórica o arte de usar las palabras para convencer agradando. Mala retórica se da cuando por falta de habilidad o exceso de confianza alguien cree sin fundamento alguno que lo que está diciendo es tan bello y atinado que llegará dulcemente a los oídos del que le está escuchando. Y mala retórica, cosa más decisiva aún, se da cuando lo que se intenta es que el otro no piense sino que quede enredado en las palabras. Es ya un lugar común distinguir entre el arte de discutir de los griegos, por un lado, y las dramatizaciones, personificaciones y exageraciones que hicieron más tarde algunos oradores Ilevados por su fe religiosa, por otro. Porque en este segundo caso no se da opción a que el otro piense sino que se le envuelve precisamente para todo lo contrario. Es éste, por cierto, un fenómeno bien actual. Si nos volvemos a muchos de los Nuevos Movimientos Religiosos podríamos comprobar hasta qué punto no se habla con alguien sino a alguien y, además, de arriba abajo. En la relación entre mayores y más jóvenes (permítaseme este paréntesis) parece que, por naturaleza, se ha de hablar desde una posición superior por parte del mayor puesto que ha acumulado experiencia y saber, algo que no le ocurre al joven. Eso es verdad. Pero incluso en estos casos no se puede aprovechar uno de la fuerza de la edad o de la posición social. De ahí que lo que se necesite sea una buena retórica. Y no es nada fácil. Porque quien quiera hablar con precisión, con acierto y aprovechando los muchos recursos que nos ofrece una lengua (sea la que estamos usando ahora o sea cualquier otra), lo debería hacer (al margen de por amor al arte) para que quien reciba el mensaje lo pueda entender mejor, saborear las palabras y disfrutar con ellas. No se debe hablar bien para imbecilizar sino para todo lo contrario. Lo cual nos lleva a la tercera y decisiva función que me interesa tocar en lo que atañe a la comunicación individual y su conexión con la ética (a través de la pedagogía).

Este punto es decisivo. El nombre de dialéctica ha tenido a lo largo de la historia distintos significados, unos positivos y otros negativos. Pero ahora vamos a tomarlo en el sentido de argumentación. Si tuviera que decir algo que considero especialmente lamentable en nuestros días es justo la incapacidad para argumentar. Da la impresión, como diría un filósofo hoy casi desconocido en nuestro país, que estamos llenos de cera en los oídos. Las malas argumentaciones están a la orden del día y acaban siempre aplastando a los ciudadanos. Al Poder (así, con mayúscula) no le suele interesar que la gente se defienda del engaño y sí, por el contrario, le viene muy bien que se trague todo. Sería muy fácil hacer un catálogo de las malas argumentaciones o falacias que recorren 
la vida pública. Que cada uno repase en su imaginación muchas de las pseudodisputas desde la política hasta las charlas de café. De esta manera nos engañan y nos autoengañamos. Es verdad que existe en nosotros una tendencia irrefrenable al autoengaño. Y es que es más fácil vivir al dictado de unos mandatos externos que poniendo a prueba nuestra libertad. Sólo que cuando esto tiene lugar lo que se resiente es nuestra capacidad moral. Por eso una tarea fundamental en la educación del ciudadano consiste en enseñarle a discutir. Lo cual exige escuchar y entender las razones de los demás. Somos excesivamente dogmáticos, no cedemos en nuestras convicciones, nos puede un tonto orgullo y pensamos que gritar mucho (característica indiscutible de este país) es estar armado de razones. Razonar es un arte difícil que se aprende ejercitándolo. Y conociendo aquello de lo que se habla. Es ridículo convertirse en tertuliano de día y de noche pontificando sobre todo lo divino y lo humano. Cuando algunos dicen de un personaje más o menos conocido que «comunica bien» es para echarse a temblar. Porque en general es el signo de que habla de cualquier cosa, imbuido por una inmensa fe en sí mismo y que uno no sabe de dónde sale. Respecto a los jóvenes (y permítaseme de nuevo la referencia a los jóvenes) la argumentación debería estar pronta a ponerse en práctica desde la infancia. No es cuestión de hacer de los niños «pequeños Pitágoras» pero sí de que vayan aprendiendo a dar razones según el desarrollo de su inteligencia.

La expresión clave es «dar razones». Todo el que profiere una oración se expone a que le pregunten el por qué de su afirmación. Y esto es especialmente relevante en ética. Si afirmo que debemos ayudar a quien lo necesite, inmediatamente se me puede preguntar por qué hemos de comportarnos de esa manera y no, por el contrario, dejar que se pudra de asco o se las arregle con el destino que le ha tocado en suerte. Las respuestas varían y son precisamente tales respuestas las que reflejan el concepto de bien en el que nos apoyamos. Quien respondiera a la citada obligación antes mentada que es mejor, o que es simplemente bueno, ayudar porque eso, a la larga, trae buenas consecuencias para todos será un utilitarista, mientras que quien considere que ayudar al necesitado es un deber de principio que nace del respeto a cada uno de los individuos, recibirá el nombre de principialista (yo me inclino más por esta segunda manera de concebir la moral y es todo un lío en la ética de nuestros días intentar conciliar una y otra postura). En cualquier caso, lo que no vale es basarse en «porque me da la gana» o en la fuerza pura. Debemos razonar en todo y debemos hacerlo especialmente en moral. De ahí que se cortaría del todo la comunicación si no somos capaces de dar razones de las actitudes que tomamos, previa elección, en nuestra vida comunitaria. Educar para la argumentación, en suma, es educar moralmente. $Y$ es algo necesario en la sociedad en la que nos ha tocado vivir. Algunos hablan, en este sentido, de la necesidad de lo que Ilaman «ética narrativa». Quieren decir con ello que poniendo modelos de vida ante los ojos o mostrando el carácter de determinadas personas enfrentadas a situaciones complicadas, aprenderíamos a razonar moralmente mejor; en otros términos, no como robots o androides sino de un modo completo, con la persona entera. 
4. Es hora de pasar a la segunda parte y contemplar la comunicación, siempre bajo el prisma de la ética, desde el conjunto de la sociedad. Y la mejor manera de entrar de lleno en esta parte, que es el núcleo del artículo, es comenzar con una batería de preguntas. Porque, ¿quiénes son los propietarios de la comunicación, de la información, de las noticias y de los silencios? ¿Quiénes y cómo se seleccionan los mensajes, se distorsionan, se reorientan en la dirección interesada o se bombardean las neuronas del ciudadano con bagatelas que no sirven ni para pasar el tiempo? Éstas son preguntas decisivas que atañen al Ilamado cuarto poder; al poder de los Medios de Comunicación en sus diversas formas. Para desarrollar esta parte, haré primero una exposición o descripción de cómo veo el estado actual de los canales de comunicación en nuestro país (y que a buen seguro son extrapolables a otros con historia y cultura política no distintas de la nuestra) y después lo juzgaré desde el punto de vista moral.

Es obvio que ya en la misma descripción se irá viendo cuál es la postura moral que luego haré más explícita. Y por «medio de comunicación» entenderé lo que familiarmente se conoce por tal: desde las televisiones hasta las revistas, pasando por los diarios. Naturalmente que no todos influyen de la misma manera. La televisión, por ejemplo, posee una capacidad de llegar al individuo, a través de la imagen, que está ausente en los otros medios o canales. En un reciente estudio sobre lo que la gente sabe de medicina o cuáles son sus fuentes de información sobre temas relacionados con la salud, la televisión se situaba en primer lugar con una notable diferencia respecto a los otros media. La credibilidad era mucho mayor si procedía de aquello que se ve; y ello a pesar de que los programas sobre salud no son tan abundantes como otros que nos inundan a través de la tv, ese reciente invento sobre el cual y a estas alturas existen no pocos tratados tanto para denigrarlo como para enaltecerlo. Dentro de los medios de comunicación, y conviene no olvidarlo, la muy reciente aparición de Internet está revolucionando todo². Aun así, no ha llegado a constituirse en lo que podríamos denominar factor decisivo de influencia comunicativa. La televisión y la radio continúan siendo los canales que, por la vista y por el oído, son como la comida al cuerpo. La gente metaboliza a su manera lo que escucha y oye todos los días, y es así como va formando su pequeña o menos pequeña cultura políticosocial. En este apartado y en relación a Internet, aunque sólo sea como indicación, no desearía olvidar toda una literatura hecha de panfletos (los panfletos han sido decisivos en las grandes revoluciones), polémicas, mensajes, y hasta cómics, que conforman una interesante red de comunicación. Entre los jóvenes esto comienza a ser relativamente habitual. En cualquier caso, se trata de algo marginal que toca sólo los bordes de la sociedad. Es todo un interrogante cuánto conseguirá ese pequeño núcleo alternativo que, en lucha contra el utilitarismo consumista de nuestro desigual planeta, intenta mostrar que otro mundo (son ésas sus palabras y yo las hago mías) es posible. Pasemos ya a la descripción del funcionamiento de los medios de comunicación.

${ }^{2}$ Dejo de lado otros aspectos virtuales o de simulación propios de una más sofisticada comunicación pero que son aplicables, fundamentalmente, a las ciencias. 
Lo primero que Ilama la atención es el inmenso poder que poseen los medios citados. La vida política, por ejemplo, discurre por ellos y otras instancias, que en democracia serían teóricamente mucho más importantes y decisivas (piénsese, por ejemplo, en el Parlamento), quedan relegadas a un segundo lugar. Su poder asusta. No ya porque tales medios marcan lo que ocurre y tachan lo que no quieren que salga a la luz sino porque crean núcleos intocables de tabúes que se asemejan a lo que sucede en las concepciones religiosas de lo sagrado. Es lo que Chomsky llama «lo tácito». Se trata de una zona acotada, intocable, que todo el mundo conoce pero sobre la cual nadie dice una palabra. Eso sí, si por alguna razón se abre la veda, todos aquellos que tenían la boca cerrada o cantaban a coro la canción correcta, cambian de postura y, dado que hay pista libre, no paran de hablar o cambian tranquilamente de canción. Las líneas del poder mediático, además, están trazadas de tal modo que sus diarios o cadenas (si nos ceñimos a la imagen y a los periódicos) están entrelazados con los partidos políticos (y que son, en principio, dos los que se reparten el poder) propios de nuestra sociedad. A veces no es fácil saber si es un periódico el que da vida a un partido o, por el contrario, un partido el que da vida a un periódico. De ahí que, pasando ahora a las cadenas de radio, si uno escucha la cadena $X$ parece que está en un país distinto al que se dibuja en la cadena Y. Lo que para una es la noticia sustancial, en la otra se silencia o viceversa. De ahí esa situación paradójica que estamos viviendo. Sin grandes diferencias de fondo entre los dos grandes partidos estatales (por diferencias de fondo me refiero a las clásicas: modelo económico, reparto de riqueza o cosas semejantes), existen, sin embargo, tribus que se enfrentan con una ferocidad verdaderamente primitiva. Da la impresión de que sólo existen dos mundos: el del clan o la tribu A y el del clan o la tribu B. Y cada uno exige lealtad absoluta. De ahí que quien se coloque en medio o un día dé la razón a uno y al día siguiente al otro (si considera que es eso lo justo) será arrojado rápidamente a las tinieblas exteriores.

La consecuencia es una ausencia Ilamativa de espacios libres. Y otra consecuencia es la ausencia de auténticos debates. Un debate, por definición y si es democrático, ha de ser abierto, con fair-play y con la disposición de cambiar si se cree que el contrario ha aportado las razones suficientes como para cambiar el propio punto de vista. Creo que lo que, sucintamente, acabo de exponer es fiel a la realidad. Pero si todo esto es así, lo que sale perdiendo es la libertad ideológica. Se crean unos bloques sin fisuras, se infraideologiza todo en el sentido antes mencionado (fidelidad al puesto de mando y poco más) y ahí se acaba la cuestión. Como consecuencia no es fácil escuchar o leer una polémica real sobre temas reales y en donde prime, antes que la obediencia debida al medio de comunicación correspondiente, el deseo de que salga a la luz la verdad sobre aquello sobre lo que se opine. $\mathrm{O}$, al menos, que se sea sincero en el asunto del que se trate. Los ejemplos de lo que estoy diciendo son tantos que me parece inútil recurrir a ninguno. Además, quien señale libremente en una dirección es probable que sea acusado de «estar haciendo el juego a alguien». Y si, finalmente, añadimos a todo lo anterior que los medios de comunicación o son o se inscriben dentro de alguna empresa en la que lo 
que importa es el negocio, el círculo se ha completado. El dinero pone el broche último a la falta de independencia, a la manipulación, a la marginación o a lo que sea.

Se me objetará inmediatamente que estoy ofreciendo un panorama desolador, que exagero o que lo que afirmo es una especie de escepticismo venenoso que paraliza al ciudadano. Cuando, por el contrario, lo que deberíamos hacer, desde una actitud moral, es imprimir, dentro de lo posible, el virus de la crítica razonable, la participación sensata y el alejamiento de cualquier postura que irracionalmente utópica conduzca a males peores. ¿Qué responder a esto? Sinceramente no pienso que he exagerado. Más aún, es difícil que, al menos en conversaciones privadas, lo niegue nadie. Otra cosa es que haya dejado en la sombra los bienes, y que no son pocos, que nos ofrecen también los diversos medios de comunicación. Esto último no lo dudo. A ellos debemos el conocer lo que, en caso contrario, quedaría en el secreto de estado, o el darnos día a día noticia de los avances tecnocientíficos actuales, o la opinión de personas que, por difícil que esto sea, saben sacar la cabeza por encima de la mediocridad e incitar al pensamiento. Más aún, los puntos de vista tan dispares a los que antes aludí son también ocasión para espabilar la inercia de aquellos que, como sucede en las dictaduras, creen a pies juntillas sólo una de las muchas versiones que suele presentar la realidad. He participado, y permítaseme este toque personal, en la vida interna de más de un periódico y sé de la abnegación de muchos periodistas, de la dificultad de perseguir una noticia o de las consecuencias positivas que pueden tener lo que exponen o comentan. Pero una vez concedido esto, añado que la tarea del filósofo moral debe ser, por encima de todo, la de señalar los errores y las deficiencias. Jaleadores de lo que existe ya hay bastantes. Si queremos transformar, siquiera mínimamente, la realidad a favor de una sana convivencia (que está en nuestras manos construir) no tenemos más remedio que poner el dedo en la llaga y dejarnos de adulaciones o de inclinarnos, fatalmente, ante lo que existe como si fuera el último logro de nuestra libertad. Pero esto nos coloca ya en la crítica moral de la comunicación.

Si lo que hemos visto anteriormente es lo que sucede, ¿qué decir desde un punto de vista ético? Antes de responder a la pregunta conviene que fije algo más en qué sentido estoy hablando de ética o moral. Porque, como es sabido y en su momento hice referencia a ello, no todos comparten el mismo concepto de bien. De ahí las diferencias que, incluso estando sometidas a las mismas presiones ambientales, tenemos unos y otros. En cualquier caso, daré por supuesto un mínimo concepto de bien que incluya como aspectos esenciales de la vida en común los siguientes: respeto a la autonomía de los individuos, rechazo de la coacción, violencia o engaño, igualdad de oportunidades y reparto equitativo de deberes y derechos. Es desde tal concepto de bien desde donde daré brevemente mi juicio respecto a la comunicación; y, más en concreto, respecto a los medios de comunicación, que es lo que nos interesa. No poco de ese juicio lo he adelantado ya. Pero deseo rematarlo ahora. 
Partiendo de una ética que quiera promover los derechos de los ciudadanos, educar y culturizar a la gente de modo que todos puedan ejercer la democracia de manera efectiva y no meramente nominal (o en la ceremonia de un voto cada cuatro años mientras que el resto del tiempo se les ha dejado en terreno de secano) habría que decir lo siguiente. No podemos estar de acuerdo con las divisiones ficticias que responden a intereses meramente particulares. De esta forma no fluye la comunicación, se interfiere en los contenidos informativos hasta desfigurarlos y, en consecuencia, la opinión pública se minimiza. Se ha clausurado de tal manera la comunicación que el intercambio público de opiniones, la capacidad de intervenir asintiendo u oponiéndose a las políticas gubernamentales se debilita. Y eso no está bien. O, lo que es lo mismo, eso no se debe hacer. De ahí que sea necesario no sólo llamar la atención sobre lo que en muchos aspectos (los antes señalados) nos está pasando sino que es un deber protestar contra lo que se nos da como comunicación cuando sólo es una parte $y$, en muchas ocasiones, una parte mutilada de sus contenidos más esenciales. Formar ciudadanos (frase que se usa con tanta ampulosidad) se consigue si logramos que los canales comunicativos, y sus respectivas fuentes, lleguen hasta los que componen la comunidad de la forma más íntegra posible. Es esto lo que posibilitará que el ciudadano conozca cómo están las cosas (no olvidemos que un requisito fundamental para que una votación sea democrática consiste en tener conocimiento suficiente de lo que se vota). Pero aún más. Los medios de comunicación culturizan o inculturizan a las personas, y la cultura es el estadio previo a la moral. Merece que nos detengamos, siquiera brevemente, en este punto.

Una sociedad inculta es una sociedad predemocrática. La cultura, y algo adelantamos antes, no consiste en asistir a conciertos o vestir a la moda. Cierta burguesía española bastante extendida muestra una escisión total entre su porte externo y su vacuidad interna. Porque no alimenta su vida cultural. Ésta, como nos lo señala ya su etimología misma, consiste en cultivarse. De ahí que se distinga entre cultura externa e interna. La externa se manifiesta en las obras de arte $u$ otros artificios salidos del ingenio humano. Tal cultura está reservada a unos pocos. Pero existe, y esto es decisivo, la cultura interna y que afecta a todo el mundo. Ésta se resume en poseer habilidades, estar atento a lo que ocurre, no perder nunca la disposición de aprender, estar abierto a lo inédito, no clausurarse nunca sino saber que el conocimiento aumenta y se modifica. $Y$, sobre todo, tener la disposición para cambiar de manera de pensar si los argumentos que se nos ofrecen nos invitan a ello. No diré que los medios de comunicación son los responsables primeros de que los ciudadanos vayan desarrollando la cultura a la que acabo de referirme. Para eso está la escuela, otro tipo de instituciones y la familia, Ahora bien, supuesto lo anterior, es un hecho que, como en su momento indiqué, los medios de comunicación suelen ser los vehículos por los que corre la cultura, en el grado que sea. No es la lectura, desgraciadamente reservada a unos pocos, sino los mensajes mediáticos los que conforman la cultura de nuestros pueblos. De ahí la responsabilidad de tales medios de comunicación. Y de ahí la necesidad de que sepan despertar 
en los oyentes o lectores el interés por una vida independiente, rica en afectos y abierta al conocimiento. La ética de la cultura, en consecuencia, insistirá, oportuna e inoportunamente, en que se debe vivir mejor y que para ello es necesario que la comunicación sea recíproca e igualitaria, y no se desenvuelva de arriba abajo y en función de los intereses de unos pocos. Y la ética de la comunicación, dicho sintéticamente, protestará cuando el estado de cosas sea como el que hemos descrito anteriormente y en el que se hace patente que la moral, tal y como la hemos definido, es muy pobre.

5. Acabo ya. Las propuestas que podría hacer se derivan de las críticas que hemos ido vertiendo a lo largo de la exposición. Lo que no tengo es vara mágica alguna para que se inviertan las cosas allí en donde tal inversión es necesaria. Para bien o para mal, la ética no es coactiva. Se limita (además de a presentar modelos de vida) a dar razones de por qué se debe actuar de una manera y no de otra y, cosa importantísima, insistirá una y otra vez que haciendo lo que debemos hacer vamos a vivir mejor; usando una expresión que suele sonar bien a nuestros oídos: seremos más felices. Por eso, si nos volvemos ahora, a modo de resumen, a las dos partes de lo que hemos venido viendo diremos lo siguiente. Por un lado, que la comunicación es fundamental en la interacción de los individuos. No hay realización de lo más personal sin comunicación. Y, como consecuencia de ello, es necesario poner todo el empeño del mundo en educar de tal manera que sepamos hablar dando razones, intercambiando sentimientos y aumentando, mutuamente, los conocimientos que acumulamos. Y, por otro lado, que los medios de comunicación, dado su poder y capacidad de influencia en la sociedad, son sumamente responsables en la difusión de la verdad y en la formación del carácter cultural de cada uno de nosotros. La ética de la comunicación, y así acabo de verdad, no es un brindis al sol. Describe lo que nos está ocurriendo. Y, sin tirar nunca la toalla, señala hacia un ideal en el que, por saber comunicarnos, haremos (o haríamos) de nuestra sociedad un lugar en el que podríamos vivir mucho más felizmente de lo que en este momento lo hacemos. 